\title{
Contact Stress and Shear Stress Analysis of Spur Gear Using ANSYS and Theoretical
}

\author{
Putti Srinivasa Rao \\ Professor, Dept.of Mechanical Engineering, \\ Andhra University College of Engineering (A), \\ Visakhapatnam, Andhra Pradesh, \\ India.
}

\author{
Ch.Vamsi \\ B.E+M.E Project Student, Dept. of Mechanical \\ Engineering, Andhra University College of \\ Engineering (A), Visakhapatnam, \\ Andhra Pradesh, India.
}

\begin{abstract}
In this paper the bending stress over the lower addendum of the spur gear, shear and contact stresses by using the software tools like pro-e and ANSYS are employed to design and analysis. Here in, we report the contact stress analysis of stainless steel spur gears by theoretical method using Hertz equations and by finite element analysis using FEA software ANSYS 15.0 workbench. The spur gear is sketched and modelled in ANSYS design modeller and the contact stress analysis is done in mechanical ANSYS multi-physics. The ANSYS software avoids tedious calculations presumably impending in the design procedure and uses ultimate numerical tool to approximate the solution of the partial differential equations associated with continuity, momentum and energy phases of a flow problem in a 3-D model. The designed 3-D model from Pro-E is inhibited in the ANSYS. This exquisite feature of ANSYS enables designer to optimize the design procedure in an iterative manner based on the final plots of post-processing phase.
\end{abstract}

Keywords: Spur Gear, Contact stresses, Shear stress, Maximum principle stress, Hertz equation, Lewis Bend Strength Equation.

\section{INTRODUCTION}

Spur gears use no intermediate link or connector and transmit the motion by direct contact. The two bodies have either a rolling or a sliding motion along the tangent at the point. No motion is possible along the common normal as that will either break the contact or one body will tend to penetrate into the other. Spur gears or straight-cut gears are the simplest type of gear. Spur gears have been used since ancient times. Modern gears are a refinement of the wheel and axle. Gear wheels have projections called teeth that are designed to intersect the teeth of another gear. When gear teeth fit together or interlock in this manner they are said to be in Mesh. Gears in mesh are capable of transmitting force and motion alternately from one gear to another. The gear transmitting the force or motion is called the drive gear and the gear connected to the drive gear is called the driven gear. Gears are more vulnerable to scuffing when they are new and their tooth surfaces have not yet been smooth end by run-in. Therefore, scuffing is the most immediate failure mode that must be dealt with. The other failure modes become simply irrelevant on gear scuffs. In other words, any well designed and manufactured gear set has the hurdle of avoiding scuffing before other considerations come to play

\section{Problem Formulation and Modelling}

The input parameters may vary place to place i.e. someone might give outer diameter and pitch diameter instead of module or Diametral pitch. All other necessary parameters like pitch circle diameter, root diameter, base circle diameter etc. are derived using standard set of gear formulas and the input parameters $[1,2,3,4]$. These gears mesh together correctly only if fitted to parallel shafts.

\subsection{Analysis of Spur Gear using ANSYS}

The two dimensional models Fatigue or yielding of a gear tooth due to excessive bending stress is two important gear design considerations. When meshing the teeth in ANSYS, if - Smart size is used the number of elements near the roots of the teeth are automatically are much greater than in other places. Three dimensional models in this section the tooth root stresses and the tooth deflection of one tooth of a spur gear is calculated using an ANSYS model. For the bending stress, the numerical result is compared with the values given by the draft proposal of the standards of AGMA. 


\section{Theoretical Calculations of Contact and Shear Stress of Spur Gear}

Calculating the Contact Stress and Shear stress of the Spur Gear with the equations which are derived from the respective theoretical calculations by which their values are dependent on the material properties of the respective materials

\subsection{Contact Stress Calculations using Hertz Equation}

To determine the contact stress $[5,6,7]$ between a pair of teeth while transmitting power by treating the pair of teeth in contact as cylinders of radii equal to the radii of curvature of the mating involutes at the pitch point.

$\sigma_{\mathrm{c}}=\sqrt{\frac{F\left(1+\frac{R_{1}}{R_{2}}\right)}{R_{1} B \pi\left(\frac{1-\mu_{1}{ }^{2}}{E_{1}}+\frac{1-\mu_{2}{ }^{2}}{E_{2}}\right)}}$

$\sigma_{\mathrm{c}}=$ Maximum Value of Contact stress $\left(\mathrm{N} / \mathrm{mm}^{2}\right)$

$\mathrm{F} \quad=$ Force pressing the two cylinders together $(\mathrm{N})$

$\mathrm{B} \quad=$ Face Width $(\mathrm{mm})$

$\mu_{1} \quad=$ Poisson's ratio of the one Cylinder

$\mu_{2} \quad=$ Poisson's ratio of the second cylinder

$E_{1}=$ Modulus of Elasticity of one cylinder $\left(\mathrm{N} / \mathrm{mm}^{2}\right)$

$\mathrm{E}_{2} \quad=$ Modulus of Elasticity of Second cylinder $\left(\mathrm{N} / \mathrm{mm}^{2}\right)$

Whereas $r_{p 1}$ and $r_{p 2}$ are the pitch radii of the pinion and gear and $\Phi$ is the pressure angel. The stress correlations derived are and in equation (1) are based on a number of simplifying assumptions, such as pure bending of short beam and elliptic distribution of stresses at tooth contact. The elastic compression of two-dimensional bodies in contact cannot be calculated solely from the contact stresses given by Hertz theory. The pitting problems, design needs and safety requirements make far in depth and complicated study of this contact. The current project aims to arriving at these very solutions. Based on the obtained results, they came to the conclusion that the hardness of the gear tooth profile can be improved to resisting failure.

3.1.1. Model Calculation of Contact Stress by HERTZ Equation

Torque $=$ Force $(\mathrm{F}) *$ Shaft Radius $\left(\mathrm{R}_{\mathrm{s}}\right)$

$1694.7725 \mathrm{e} 3(\mathrm{~N}-\mathrm{mm})=\mathrm{F} * 31.75$

$\mathrm{F}=53378.6614 \mathrm{~N}$

$\sigma_{\mathrm{c}}=\sqrt{\frac{F\left(1+\frac{R_{1}}{R_{2}}\right)}{R_{1} B \pi\left(\frac{1-\mu_{1}^{2}}{E_{1}}+\frac{1-\mu_{2}{ }^{2}}{E_{2}}\right)}}$

$$
=\sqrt{\frac{53378.6614\left(1+\frac{63.5}{63.5}\right)}{63.5 * 25.4 \pi\left(\frac{1-0.28^{2}}{130 * 10^{3}}+\frac{1-0.28^{2}}{130 * 10^{3}}\right)}}
$$

Contact stress from hertz equation is $\sigma_{\mathrm{c}}=2090.5 \mathrm{MPa}$.

\subsection{Shear Stress using Lewis Bend Strength Equation}

The effect of the fillet, at the tooth pair, on the stress concentration is ignored. For the cantilever formed tooth, the maximum stress $[8,9]$ is found at the tooth root. The application of the standard bending stress equation $(\mathrm{S}=\mathrm{M} / \mathrm{Z})$ leads to:

$\mathrm{S}=\frac{6 F_{t} h}{b t^{2}}$

$\mathrm{S}=$ Bending stress in gear tooth

$F_{t}=$ Tangential tooth load

$h=$ tooth depth

$b=$ Face width

$t=$ Tooth thickness

The normal force is assumed to be uniformly distributed along the face width in equation (2). The factor $\mathrm{t}^{2} / 6 \mathrm{~h}$ is a geometrical property of the size and shape of the tooth. It may be expressed as function of the circular pitch $\mathrm{P}_{\mathrm{c}}$ by relation: 
$\mathrm{t}^{2} / 6 \mathrm{~h}=\mathrm{y}^{*} \mathrm{p}_{\mathrm{c}}$

Where y is an abstract number known as Lewis form factor.

The compressive stress due to the radial load, Fr can be shown equal to:

$\mathrm{S}_{\mathrm{c}}=\frac{F_{r}}{b * t}$

$\mathrm{Sc}=\frac{F_{t} * \tan \Phi}{b * \sqrt{\frac{6 * h * Y}{P_{d}}}}$

But the tooth depth, $\mathrm{h}=2.157 / \mathrm{Pd}$

$\mathrm{S}_{\mathrm{c}}=\frac{F_{t} * \tan \Phi}{b * \sqrt{\frac{6 * 2.157 * Y}{P_{d^{* P} d}}}}$

$\mathrm{S}_{\mathrm{c}}=\frac{F_{t} * 0.28 * \tan \Phi * P_{d}}{b * Y^{0.5}}$

Where $S_{\mathrm{e}}$ is the elastic limit in tension. In the case of combined load the member will fail when its maximum shear stress at equation (6) exceeds the elastic limit in shear, in other words:

For a pressure angle of $20, \tan \Phi=0.364$.

$\mathrm{S}_{\mathrm{s}}=\frac{\mathrm{F}_{\mathrm{t}} * 0.28 * \tan \Phi * \mathrm{P}_{\mathrm{d}}}{\mathrm{b} * \mathrm{Y}^{0.5}} \sqrt{1+0.25 \mathrm{Y}^{0.5}+0.32 \mathrm{Y}}$

3.2.1. Model Calculation of Contact Stress by Lewis Bend Strength equation

Torque $=$ Force $(\mathrm{F}) *$ Shaft Radius $\left(\mathrm{R}_{\mathrm{s}}\right)$

$1694.7725 \mathrm{e} 3(\mathrm{~N}-\mathrm{mm})=\mathrm{F} * 31.75$

$\mathrm{F}_{\mathrm{t}}=53378.6614 \mathrm{~N}$

$\mathrm{S}_{\mathrm{s}}=\frac{F_{t} P_{d}}{2 b Y} \sqrt{1+0.25 Y^{0.5}+0.32 Y}$

$\mathrm{S}_{\mathrm{s}}=\frac{53378.6614 * 0.157}{2 * 25.4 * 0.3} \sqrt{1+0.25(0.3)^{0.5}+0.32(0.3)}$

$=8140.426 \mathrm{~N} / \mathrm{Mm}^{2}$

\section{STATIC STRUCTURAL ANALYSIS OF SPUR GEAR USING ANSYS}

Structural analysis is the determination of the effects of loads on physical structures and their components. The finite element method approximates a structure as an assembly of elements or components with various forms of connection between them and each element of which has an associated stiffness. The results or solutions which are obtained from the Static Structural analysis from the ANSYS $[10,11,12,13]$ to the respective materials which are taken into the consideration from which the resultant oriented from them are taken.

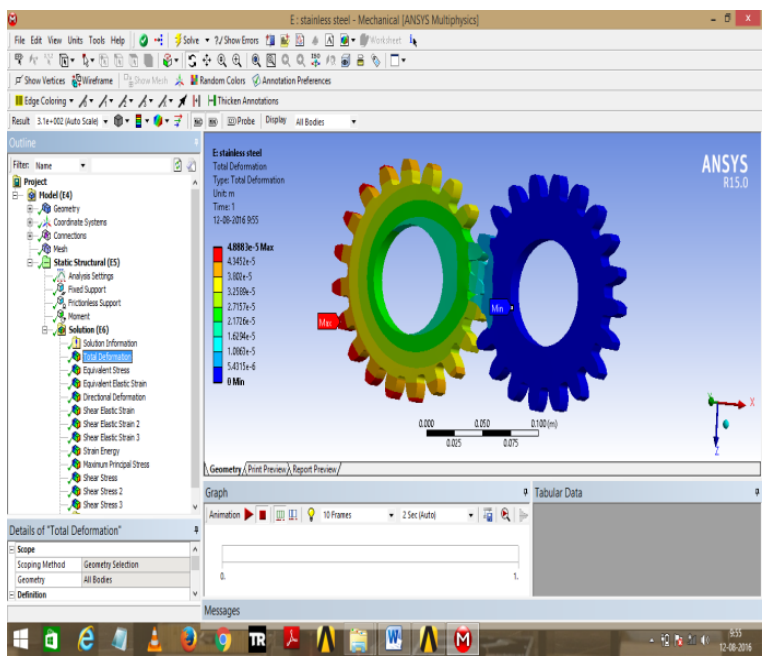

Fig1. Total Deformation

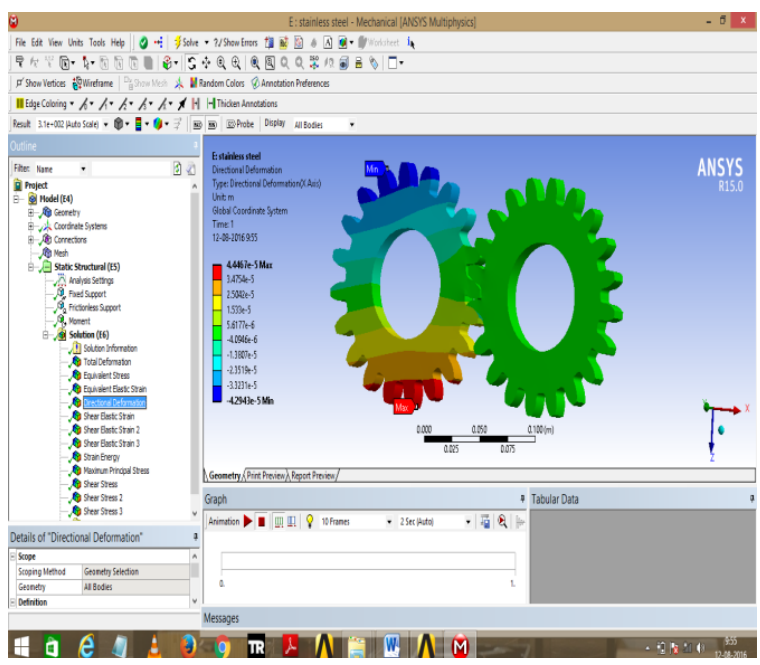

Fig2. Directional Deformation 


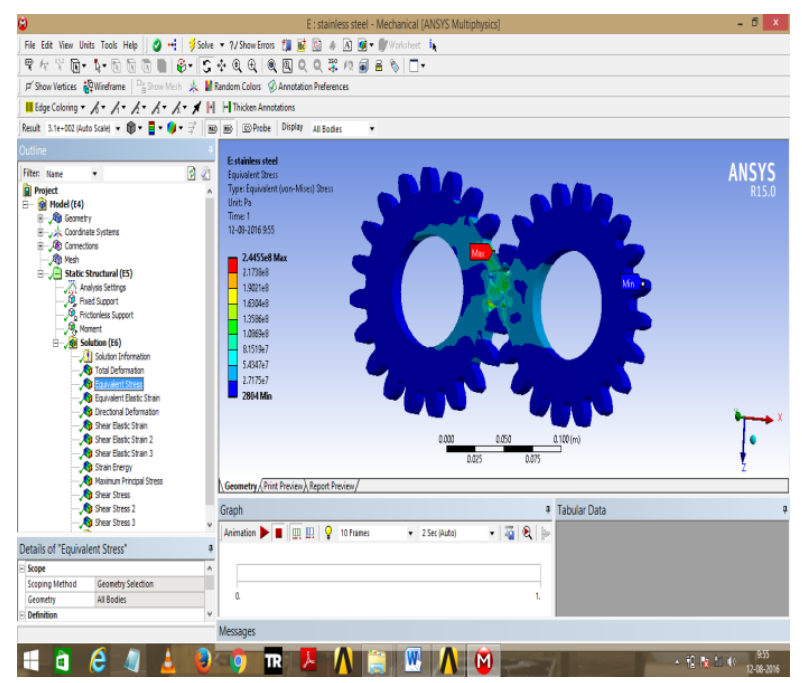

Fig3. Equivalent stress

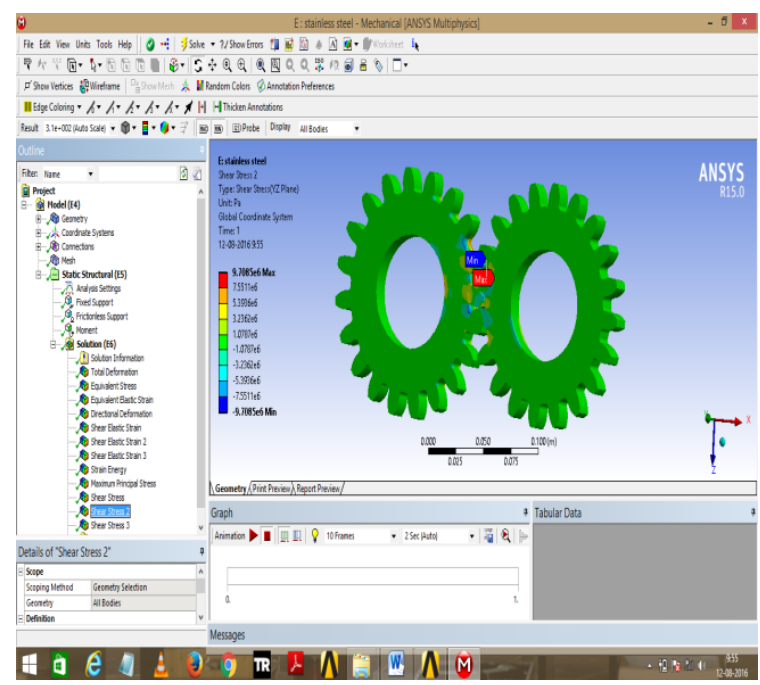

Fig4. Shear Stress

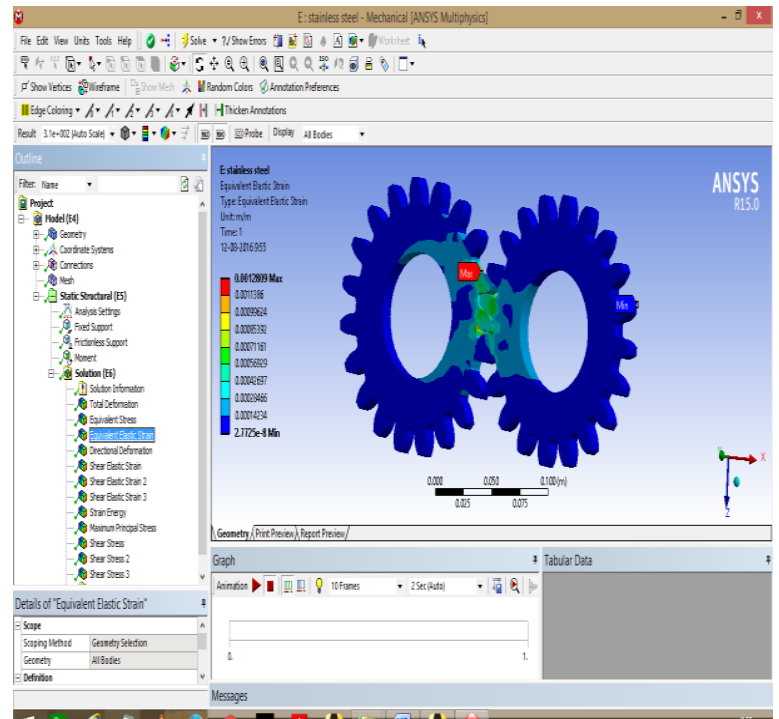

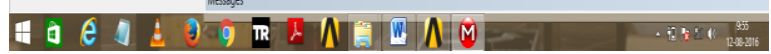

Fig5. Equivalent Elastic Strain

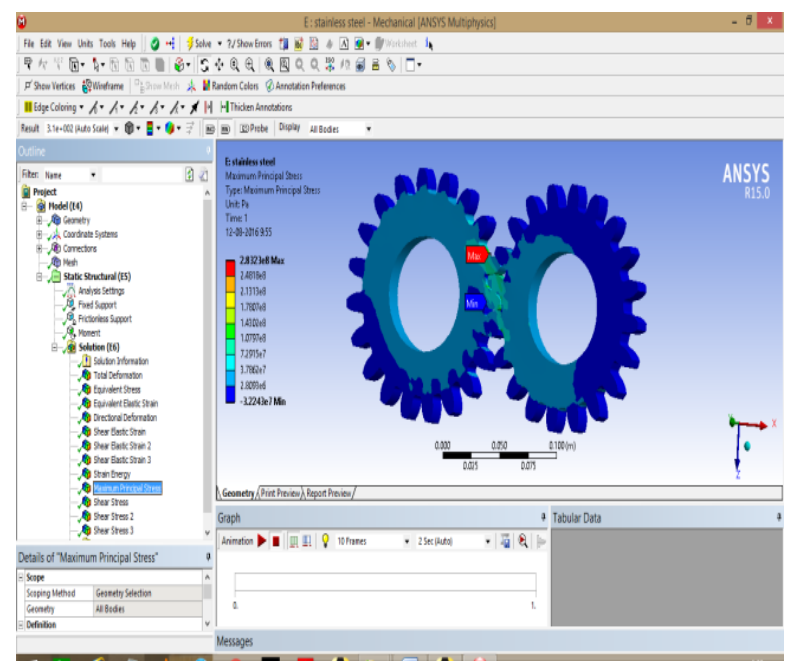

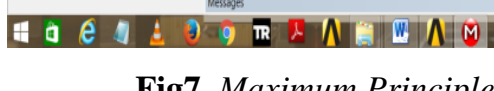
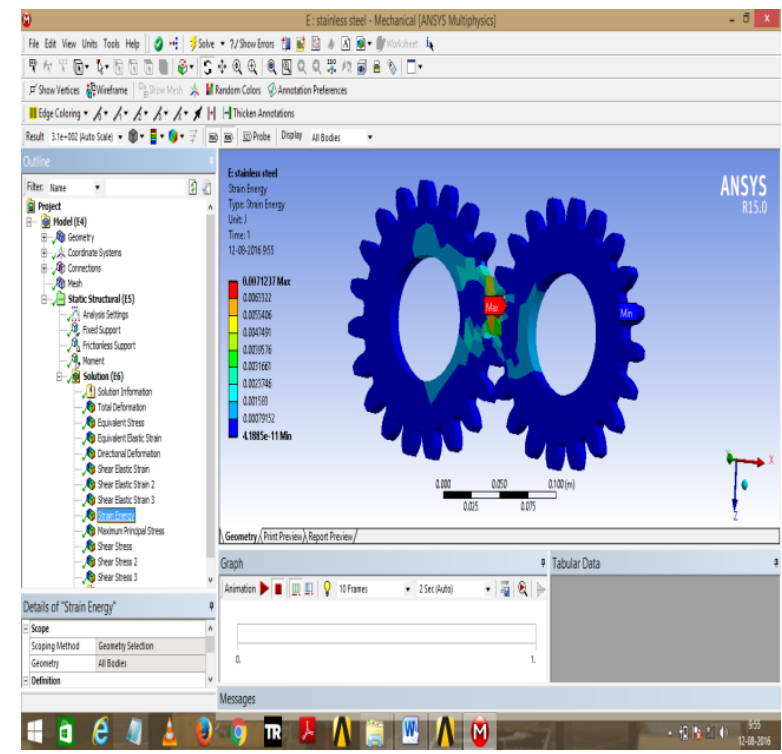

Fig6. Strain Energy

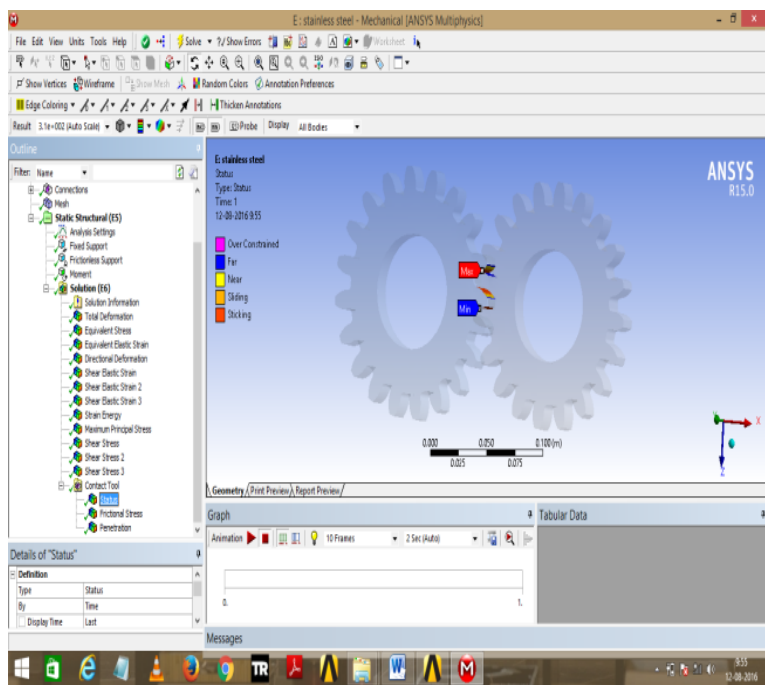

Fig 8. Contact tool Status 


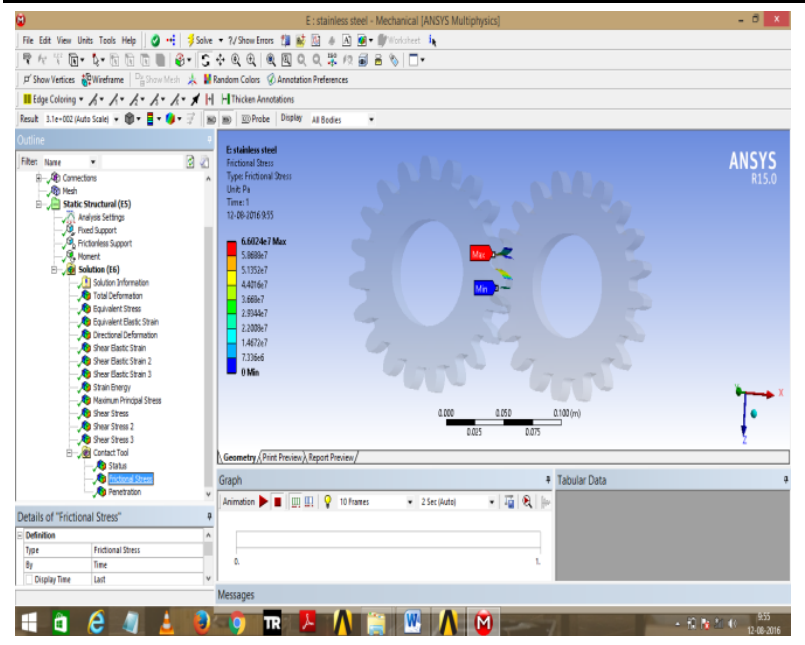

Fig9. Frictional Stress

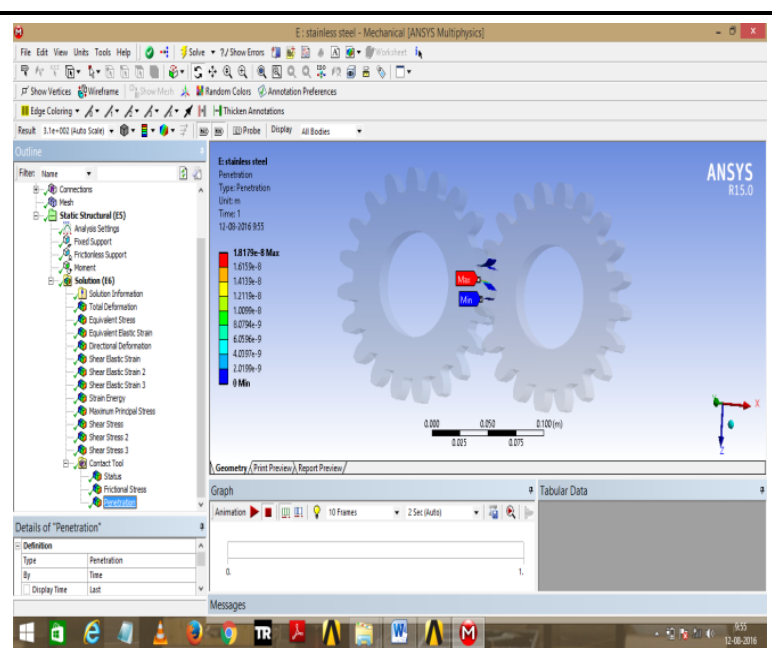

Fig10. Penetration

The use of different materials in gear manufacturing provides a range of contact stresses and shear stress. This range of contact stresses and shear stress is useful in the selection of material in different applications. The use of different materials in gear manufacturing provides a range of contact stresses and the obtained values are tabulated in the table 1.

Table1. Contact Stress and Shear Stress for different materials.

\begin{tabular}{|c|c|c|}
\hline Material & Equivalent Stress & Shear Stress \\
\hline Stainless Steel & $2.4445 \mathrm{e} 8$ & 9708.5 \\
\hline Structural Steel & $2.4432 \mathrm{e} 8$ & 9374.9 \\
\hline Copper Alloy & $2.4258 \mathrm{e} 8$ & 10039.9 \\
\hline Gray Cast Iron & $2.3794 \mathrm{e} 8$ & 8476.6 \\
\hline Aluminum Alloy & $2.4158 \mathrm{e} 8$ & 10047.7 \\
\hline
\end{tabular}

\section{RESULTS AND DISCUSSIONS}

The use of different materials in gear manufacturing provides a range of contact stresses. This range of contact stresses and deformation is useful in the selection of material in different applications. The values obtained by Hertz's equation and ANSYS agree with each other with each other with a maximum error. The contact pressure and stress state are highest for higher points on the involute and lower were a single pair of teeth assumes the full load transmitted, and minimal for the contact at the pitch point. The Contact stresses from ANSYS and Hertz equation are tabulated in the table 2. The Shear stresses from ANSYS and Lewis Bend Strength equation are tabulated in table 3.

Table2. Contact stress results comparison

\begin{tabular}{|c|c|c|c|}
\hline \multirow{2}{*}{ Materials } & \multicolumn{3}{|c|}{ Contact Stress(MPa) } \\
\cline { 2 - 4 } & ANSYS & HERTZ Equation Values & Error \% \\
\hline Structural Steel & 2443.2 & 2381.7 & 2.58 \\
\hline Stainless Steel & 2443.3 & 2308.6 & 5.83 \\
\hline Gray cast iron & 2379.4 & 2090.5 & 13.8 \\
\hline Aluminum Alloy & 2415.3 & 2048.9 & 9.16 \\
\hline Copper Alloy & 2425.3 & 2224.5 & \\
\hline
\end{tabular}

Table3. Shear stress results Comparison

\begin{tabular}{|c|c|c|c|}
\hline \multirow{2}{*}{ Materials } & \multicolumn{3}{|c|}{ Contact Stress (MPa) } \\
\cline { 2 - 4 } & ANSYS & Lewis Bend Strength & Error \% \\
\hline Structural Steel & 9374.9 & 8140.426 & 19 \\
\hline Stainless Steel & 9708.5 & 8140.426 & 4.2 \\
\hline Gray cast iron & 8476.6 & 8140.426 & 23.4 \\
\hline Aluminum Alloy & 10047.7 & 8140.426 & 23 \\
\hline Copper Alloy & 10039.9 & 8140.426 & \\
\hline
\end{tabular}

Structural steel has high Young's Modulus and Poisson's Ratio which is responsible for its high contact stress. The values are compared to practical values and the two analysis validate each other. 
Gray Cast Iron has high Compressive strength and Resistance to deformation which is responsible for its high Shear stress. The values are compared to practical values and the two analyses validate each other. The elasticity of those bodies modifies the contact between loaded tooth pairs and the transmission error variations. The developed numerical method allows one to optimize the static transmission error characteristics by introducing the suitable tooth modifications.

\section{REFERENCES}

[1] Gupta, Mr Bharat, Mr Abhishek Choubey, and Mr Gautam V. Varde. "Contact stress analysis of spur gear."In International Journal of Engineering Research and Technology, vol. 1, no. 4, ESRSA Publications, June-2012.

[2] Rani, T.Shoba, and T.Dada Khalandar. "SPUR GEAR." International Journal of Computational Engineering Research, Vol. 3, no. 11, pp 7-12, 2013.

[3] Bhandari, V. B, "Design of machine elements", Tata McGraw-Hill Education, 2010

[4] Lee, Huei-Huang. Finite element simulations with ANSYS workbench 15.SDC publications, 2012.

[5] Karaveer, Vivek, Ashish Mogrekar, and T. Preman Reynold Joseph. "Modeling and Finite Element Analysis of Spur Gear." International Journal of Current Engineering and Technology, ISSN: 2277-4106, 2013

[6] M. Raja Roy,S. PhaniKumar, D.S. Sai Ravi Kiran, "Contact pressure analysis of spur gear using FEA", International Journal of Advanced Engineering Applications, Vol.7, Iss.3, pp.27-41 (2014)

[7] Putti Srinivasa Rao, Nadipalli Sriraj, Mohammad Farookh, "Contact Stress Analysis of Spur Gear for Different Materials using ANSYS and Hertz Equation" International Journal of Modern Studies in Mechanical Engineering (IJMSME), Volume 1, Issue 1, pp 45-52, June 2015.

[8] Umezawa, K., , "Recent Trends in Gearing Technology", JSME International Journal Series III, Vol.31, No. 2, pp 357-362

[9] Salan Gasim Ahmed, Maximum Shear Stress Analysis of Spur Gear Strength, JSME, International Journal Series, Vol. 7,pp 31-36, Oct 2013

[10] Putti Srinivasa Rao, Revu Venkatesh, "Static and Transient Analysis of leaf spring Using Composite Material" IUP Journal of Mechanical Engineering, September-November 2015 (ISSN: 0974-6536).

[11] Putti Srinivasa Rao, Ch. Ratnam, “ Experimental and Analytical Modal Analysis of welded Structure Used For Vibration Based Damage Identification" Global Journal of researches in engineering Mechanical and mechanics engineering, Volume 12, Issue 1, pp 45-50, January 2012, Published by Global Journals Inc. (USA) (ISSN Print: 0975-5861, ISSN Online:22494596).

[12] Gagandeep Singh., "Increasing Life of Spur Gears with the Help of Finite Element Analysis", International Journal of Recent advances in Mechanical Engineering (IJMECH) Vol.3, No.3, Aug - 2014. 